\title{
Sympathetic Skin Response in Children with Iron Deficiency Anemia
}

\author{
Abdurrahman Sönmezler, Mahmut Abuhandan, Tahir Kurtulus Yoldas, \\ Yeşim Oymak, Mustafa Çalık, Bülent Güzel, Hakim Çelik \\ Assistant Professor, Department of Neurology, \\ Adana City Research and Training Hospital, Adana, Turkey
}

\begin{abstract}
BACKGROUND: Iron deficiency anemia (IDA) is particularly high in children in developing countries .Sympathetic skin response (SSR) is a polysynaptic reflex, and its final efferent pathway involves pre- and post-ganglionic sympathetic sudomotor fibers that ultimately activate the sweat glands through sympathetic outflow. The aim of this study was to investigate whether IDA is involved in SSR.
\end{abstract}

METHODS: 24 patients (17 girls, 7 boys) with IDA and 20 healthy children (11 girls, 9 boys) were enrolled in the study.

RESULTS: Significant differences were observed between the palmar SSR results (latency, ms) of the patient and the control groups $(1.09 \pm 0.24,0.92 \pm 0.30, \mathrm{p}=0.048)$. There was no correlation between ferritin levels and SSR results of the patient group ( $\mathrm{p}=0.65)$.

CONCLUSIONS: The evidence from this preliminary study suggests that efferent $\mathrm{C}$ fibers of the sympathetic nervous system may not intact in IDA. The sudomotor autonomic function test may be useful to detect autonomic involvement earlier.

Keywords: Iron deficiency anemia, sympathetic skin response, children

\section{INTRODUCTION}

Iron deficiency anemia (IDA) is particularly high in children in developing countries ${ }^{1}$.Iron plays an important role in various neurometabolic processes, which can be altered by iron deficiency. Hypoxia may lead to neuronal dysfunctions in IDA $^{2}, 3,4,5,6,7,8,9$. Sympathetic skin response (SSR) is a polysynaptic reflex, and its final efferent pathway involves pre- and post-ganglionic sympathetic sudomotor fibers that ultimately activate the sweat glands through sympathetic outflow ${ }^{10}$.SSR is coordinated in the posterior hypothalamus or upper brainstem reticular formation ${ }^{11}$. The aim of this study was to investigate whether sympathetic skin responses are affected by the presence of iron deficiency anemia.

\section{Materials and methods}

This study was performed prospective at Harran University Hospital it was approved by the local ethics committee. There was informed consent obtained from the parents of all study participants. 24 children (17 girls, 7 boys, mean age $: 13.7 \pm 1.79$ ) with IDA and 20 healthy children(11 girls, 9 boys,mean age $12.4 \pm 1.93$ ) were enrolled in the study. Patients with IDA with a hemoglobin value of less than 5 gr/dl were excluded from this study. All children were thoroughly examined clinically to rule out other causes of neuropathy. Electrophysiological testing was carried out according to the Technical Standards of the International Federation of Clinical Neurophysiology ${ }^{12}$. Childrens were investigated in a dark and silent room in a supine position with their eyes closed. Body,and skin temperature was controlled, temperature were same. EMG was performed using a filter setting of $0.1-32 \mathrm{~Hz}$, a sensitivity setting of 1 $\mathrm{mV} \mathrm{div}{ }^{-1}$, and a sweep rate of $5 \mathrm{~s}$. The SSR was recorded with surface electrodes (palmar) on the skin (Electromyography machine Dantec, Keypoint, Denmark).The study data were analyzed using SPSS (Statistical Package for Social Sciences) for Windows version 11.5. Differences between groups were evaluated with the Mann-Whitney U-test. A value of $\mathrm{p}<0.05$ was accepted as statistically significant. Relations between variables were studied by the Pearson correlation test.

\section{Results}

All physical examination results of the children involved in this study were normal. The children did not report any symptoms of autonomic dysfunction. Significant differences were observed between the palmar SSR results (latency, ms) of the the children with IDA and the control groups $(1.09 \pm 0.24,0.92 \pm 0.30, p=0.048)$. There was no correlation between ferritin levels and SSR results of the the children with IDA group ( $p=0.65)$.

\section{Discussion}

The palmar SSR results of the the children with IDA were different from those of the control group. There was no correlation between ferritin levels and SSR results of the children with IDA. Iron plays an important role in various metabolic and enzymatic processes. Iron deficiency may have an effect on neurological and intellectual functions. Many of the iron containing enzymes of the central and peripheral nervous systems could be affected adversely by IDA 7,14 . SSR is coordinated in the posterior hypothalamus or upper brainstem reticular formation ${ }^{11}$. SSR is an indicator of sudomotor function mediated by amyelinic efferent Cfibers of the sympathetic nervous system ${ }^{13}$. 
IDA alters the behavior of infants in the cognitive, motor, and socio emotional domains and interferes with optimal development. Iron plays key roles in the normal progression of several neurofunctional systems. The mechanisms by which chronic iron deficiency in infancy could contribute to adverse adult outcomes are undoubtedly complex.

From animal models, it is clear that early-life iron deficiency adversely impacts the developing brain. IDA is associated with altered short and long-term neurofunctional development, including impaired myelination and dendritogenesis; altered neurotransmitter functioning; changes in neurometabolism in the hippocampus, striatum, and cortex; and altered gene and protein profiles 15, 16, 17, 18 .

In our study, there was no correlation between ferritin levels and SSR results of the children with IDA. Interestingly, we identified prolonged latency of SSR in the extremities.SSR is a polysynaptic reflex. The data may suggest that there are affected areas in the amyelinic efferent C-fibers or other parts of the reflex arc, but it is not clear. Because of the SSR is coordinated in the posterior hypothalamus or upper brainstem reticular formation. To our knowledge, there is no previous description of whether there is a correlation between ferritin levels and SSR latency in children and of differences between SSR of the children with IDA and a healthy group. This study is preliminary, and SSR in IDA should be studied in larger randomized groups. The evidence from this preliminary study suggests that efferent $C$ fibers of the sympathetic nervous system may not intact in IDA. The sudomotor autonomic function test may be useful to detect autonomic involvement earlier.

\section{Acknowledgement}

The authors have no financial or personal relationships with other people or organizations that could pose a conflict of interest in connection with the present work.

This article was presented as a poster at 7th World Congress on Controversies in Neurology (CONy)

\section{References}

[1] DeMaeyer E, Adiels-Tegman M.The prevalence of anemia in the world,World Health Stat Q 1985; 38:30216.

[2] Karabiber H, Ozgen U, Ozen C, Soylu H, Kutlu O, Sarıbaş S, Kaya M, Demir Eksikliği Anemili Cocuklarda Tedavinin Mental Skor ve Uyarılmış Potansiyellere Etkisi. Turk Hematoloji Onkoloji Dergisi 2000;10 ; 1948.

[3] Fairbanks VF, Beutler E. Iron deficiency. In: Beutler E, Lichtman MA, Coller BS, Kipps TJ, editors. Williams Haematology, Fifth edition, New York: McGraw-Hill, 1995; 490-511.
[12] Claus D, Schondorf R. In: Deuschl, G, Eisen, E (Eds.), Recommendations for the practice of clinical neurophysiology (EEG) (Suppl. 52). Elsevier,1999. 276-277.

[13] Elie B, Guiheneuc P. Sympathetic skin response: normal results in different experimental conditions. Electroencephalography and Clinical Neurophysiology 1990; 76,258-267.

[4] Beard JL, Connar JL. Iron status and neural functioning. AnnRev Nutr 2003; 23:41-58.

[5] Beard JL. Iron deficiency alters brain development and functioning. J Nutr 2003; 133:1468-72.

[6] Connor JR, Menzies SL. Relationship of iron to oligodendrocytes and myelination. Glia 1996; 17:8393.

[7] Kabakus N, Ayar A, Yoldas TK, Ulvi H, Dogan Y, Yilmaz B, Kilic N. Reversal of iron deficiency anemia-induced with iron deficiency anemia. J Trop Pediatr 2002; 48:204-9.

[8] El-Sebae AH, Soliman SA, Ahmed NS.Delayed neuropathy in sheep by the phosphonothioate insectiticide cyanofenphos. J Environ Sci Health 1979; 14:247-63.

[9] Brett EM.Vascular disorders of the nervous system in childhood. In: Brett EM (ed.), Pediatric Neurology, 3rd edn. Churchill Livingstone, New York; 1997; 579.

[10] Shahani BT, Halperin JJ, Boulu P, Cohen J. Sympathetic axon dysfunction in peripheral neuropathies. Journal of Neurology Neurosurgery and Psychiatry 1984;47,536542.

[11] GR Arunodaya, Arun B Taly. Sympathetic skin response: a decade later. Journal of the Neurological Sciences 1995; 129, 81-89.

] Lozoff B, Jimenez E, Wolf AW. Long-term developmental outcome of infants with iron deficiency. N Engl J Med 1991; 325:687-94.

[15] Lozoff B, Beard J, Connor J, et al. Long-lasting neural and behavioral effects of iron deficiency in infancy. Nutr Rev 2006; 64:S34-S43.

[16] Lozoff B. Iron deficiency and child development. FoodNutr Bull 2007; 28:560-S571.

[17] Georgieff MK. Long-term brain and behavioral consequences of early iron deficiency. Nutr Rev 2011; 69:43-S48.

[18] Lozoff B. Early iron deficiency has brain and behavior effects consistent with dopaminergic dysfunction. J Nutr 2011; 141:740-746. peripheral neuropathy by iron treatment in children skin response - a method of assessing unmyelinated 